\title{
ĐÁNH GIÁ ẢNH HƯỞNG IN VITRO CỦA GEL CHLORHEXIDINE IN SITU 0,5\% LÊN SỰ SỐNG VÀ DI CHUYỂN CỦA NGUYÊN BÀO SỢI NƯỚU NGƯỜI
}

\section{TÓM TẮT}

Gel in situ chứa 0,5\% chlorhexidine $(\mathrm{CHX})$ là một chế phẩm thử nghiệm mới từ khoa Dược, trường Đại học Y dược TPHCM. Nguyên bào sợi nướu (NBSN) là thành phẩn chính của mô nướu, đóng vai trò quan trọng trong lành thương nướu. Mục tiêu: Đánh giá ảnh hưởng của gel $\mathrm{CHX} 0,5 \%$ in situ lên sự sống và di chuyển của NBSN. Đối tượng và phương pháp nghiên cứu: Nghiên cứu in vitro có nhóm đối chứng là PerioKin ${ }^{\circledR}$ (Tây Ban Nha). Dịch chiết gel $\mathrm{CHX} 0,5 \%$ in situ được pha loãng thành 4 nồng độ $1 / 10,1 / 10^{2}$, $1 / 10^{3}$ và $1 / 10^{4}$. Độc tính tế bào được đánh giá bằng thử nghiệm MTT sau khi ủ NBSN với từng nồng độ trong 24 giờ. Ảnh hưởng của nồng độ gel an toàn tới đặc tính di chuyển của NBSN được đánh giá bằng phương pháp đường rach. Kết quả: Phần trăm sống của NBSN khi tiếp xúc với gel $\mathrm{CHX}$ pha loãng $1 / 10^{3}$ và $1 / 10^{4}$ là trên $70 \%$. Hai nồng độ an toàn này làm giảm sự di chuyển của NBSN. Kết luận: Ánh hưởng của gel CHX in situ lên NBSN phụ thuộc nồng độ và tương đương gel đối chứng.

Tư khóa: Chlorhexidine, gel in situ, gel đảo ngược nhiệt, độc tính tế bào, di chuyển.

\section{SUMMARY}

EVALUATE THE EFFECTS OF 0,5\% CHX GEL IN SITU ON THE VIABILITY AND \section{MIGRATION OF HGFS}

Background: The gel in situ containing 0,5\% chlorhexidine (CHX) is made by the Faculty of Pharmacy, University of Medicine and Pharmacy at Ho Chi Minh City. Human gingival fibroblast cells (hGFs) are one of major components of the gingival, playing an important role in wound healing. Objective: Evaluate the effects of $0,5 \% \mathrm{CHX}$ gel in situ on the viability and migration of hGFs. Materials and Methods: The gel extract was diluted into 4 concentrations of $1 / 10,1 / 10^{2}, 1 / 10^{3}$ và $1 / 10^{4}$. Cytotoxicity was assessed by MTT assay after incubation of hGFs for each concentration for 24 hours. Effect of safe concentrations on migration of hGFs was evaluated by scratch test. Results: Cells survival rate when exposed to $1 / 10^{3}$ và $1 / 10^{4}$ diluted $\mathrm{CHX}$ gel was over $70 \%$. At safe concentrations, $\mathrm{CHX}$ gel in situ reduces the migration of hGFs. Conclusion: The effect of $\mathrm{CHX}$ gel in situ on hGFs depends on its diluted concentration and wiis similar to control gel. Key words: Chlorhexidine, in situ gel, cytotoxicity, migration

${ }^{1}$ Đai hoc Y dước TP.Hồ Chí Minh

Chịu trách nhiệm chính: Trân Xuân Vĩnh

Email: vinhdentist@yahoo.com

Ngày nhận bài: 2.3.2021

Ngày phản biện khoa học: 21.4 .2021

Ngày duyệt bài: 4.5.2021

\section{Nguyễn Ngọc Hoài Bảo ${ }^{1}$, Trần Xuân Vĩnh ${ }^{1}$}

\section{I. ĐĂT VẤN ĐỀ}

Bệnh nha chu là một tình trang viêm nhiễm do vi khuẩn ảnh hưởng đến cấu trúc nâng đõ răng. Giai đoạn đầu gây viêm nướu liên quan đến sự tích tụ mảng bám răng. Giai đoạn sau là viêm nha chu, gây phá hủy mô liên kết, dây chằng nha chu và xương ổ răng. Nếu không được điều trị có thể dẫn đến mất răng [1]. Chlorhexdine $(\mathrm{CHX})$ là một hợp chất bisbiguanide và có phổ kháng khuẩn rộng. $\mathrm{CHX}$ được sử dụng để kiểm soát mảng bám và điều trị viêm nướu. CHX có nhiều dạng sử dụng, trong đó gel hình thành tại chỗ (gel in situ) ngày càng được quan tâm. Gel in situ tồn tại dạng lỏng sẽ chuyển thành dạng gel có độ bền cao khi đến vị trí tác dụng làm tăng thời gian lưu trú của hoạt chất và tăng hiệu quả điều trị [2]. Hiện nay, khoa Dược thuộc trường Đại học Y dược Thành phố Hồ Chí Minh đang nghiên cứu sản xuất một loại gel in situ chứa $\mathrm{CHX}$ với nồng độ $0,5 \%$ nhằm hỗ trợ điều trị viêm nha chu. Chế phẩm được bào chế dưới dạng gel in situ kích thích bởi nhiệt độ. Đặc điểm của sản phẩm này là công thức ở dạng lỏng trong điều kiên bảo quản và chuyển sang dạng gel trong điều kiện sinh lý $\left(37^{\circ} \mathrm{C}\right)$. Chế phẩm đang trong quá trình nghiên cứu, vì vậy chúng tôi tiến hành những thử nghiệm in vitro để đánh giá sự an toàn của chế phẩm. Hiên nay vẫn chưa có nghiên cứu in vitro nào về ảnh hưởng của loại gel in situ này lên các dòng tế bào của mô nha chu, cụ thể là nguyên bào sợi nướu người (NBSN). Vì vậy, nghiên cứu được thực hiện nhằm "Đánh giá ảnh hưởng in vitro của gel chlorhexidine in situ 0,5\% lên sự sông và di chuyển của nguyên bào sợi nướu người".

\section{II. ĐỐI TƯỢNG VÀ PHƯƠNG PHÁP NGHIÊN CỨU}

Đối tượng nghiên cứu: Gel $\mathrm{CHX}$ 0,5\% được cung cấp từ khoa Dược, trường Đại học $Y$ dược Thành phố Hồ Chí Minh. Nhóm chứng so sánh là gel $X$ (PerioKin ${ }^{\circledR}$, Tây Ban Nha) chứa 0,2\% CHX. Nghiên cứu được thực hiện tại Phòng thí nghiệm Kỹ nghệ mô và Vật liệu $Y$ sinh, trường Đại học Khoa học Tự nhiên, Đại học Quốc gia Thành phố Hồ Chí Minh.

Phương pháp nghiên cứu: Nghiên cứu in vitro có nhóm chứng.

Chuẩn bị vật liệu và tế bào: NBSN ở $\mathrm{P3}$ được nuôi ở $37^{\circ} \mathrm{C}, 5 \% \mathrm{CO}_{2}$, cấy chuyền đến $\mathrm{P} 4$ 
cho đến khi đạt mật độ khoảng 80\%. Đánh giá gel được tiến hành bằng phương pháp thử nghiệm dịch chiết. Dịch chiết từ gel thu được bằng cách ngâm $0,1 \mathrm{~g}$ gel $\mathrm{CHX} 0,5 \%$ vào $1 \mathrm{ml}$ môi trường nuôi cấy có huyết thanh rồi đem ủ 24 giờ theo tiêu chuẩn ISO10993-12:2012. Sau 24 giờ, dịch chiết được lọc qua màng lọc 0,22 $\mu \mathrm{m}$ vô trùng. Dịch chiết từ gel chưa pha loãng được xem nồng độ là $1(100 \%)$ và pha loãng bằng cách thêm vào môi trường nuôi cấy có huyết thanh thành 4 nồng độ $1 / 10,1 / 10^{2}, 1 / 10^{3}$ và $1 / 10^{4}$. Bảo quản dịch chiết ở $37^{\circ} \mathrm{C}, 5 \% \mathrm{CO}_{2}$ [3].

Đánh giá độc tính bằng thử nghiệm MTT (theo tiêu chuẩn ISO10993-5:2009): Chứng âm là môi trường nuôi cấy có huyết thanh và chứng dương là môi trường nuôi cây có huyết thanh bổ sung dung dịch DMSO 20\%. Đầu tiên, ủ $10^{3} \mathrm{NBSN} /$ giếng với $100 \mathrm{ml}$ dịch chiết đã được chuẩn bị ở $37^{\circ} \mathrm{C}, 5 \% \mathrm{CO}_{2}$. Sau 24 giờ, loại bỏ dịch chiết và thêm vào $10 \mu \mathrm{l}$ dung dịch MTT ( 5 $\mathrm{mg} / \mathrm{ml}$ ) và $90 \mu \mathrm{l}$ môi trường nuôi cấy có huyết thanh, sau đó đem đĩa ủ 4 giờ ở $37^{\circ} \mathrm{C}, 5 \% \mathrm{CO}_{2}$. Quan sát, ghi nhận các tinh thể formazan màu xanh tím được tạo ra. Hút bỏ toàn bộ dung dịch trong các giểng. Cho vào mỗi giếng $100 \mu \mathrm{l}$ dung dịch DMSO/Ethenol (tỉ lệ 1:1), huyền phù đều trong mỗi giếng để hòa tan các tinh thể formazan tạo thành dung dịch đồng nhất và tiến hành đo độ hấp thụ quang học OD ở bước sóng $570 \mathrm{~nm}$ bằng máy đo. Đánh giá định lượng bằng tỷ lệ tăng trưởng tương đối (RGR) bằng cách đo mật độ quang. Giá trị RGR càng thấp, khả năng gây độc tế bào của dịch chiết gel $\mathrm{CHX}$ càng cao. Nếu phần trăm RGR <70\%: dịch chiết gel CHX có độc tính lên tế bào. Bên cạnh đó, sau khi phân tích tỷ lệ tăng trưởng tương đối (RGR), độc tính tế bào có 5 mức độ được xếp loại theo bảng 1 [4].

Bảng 1. Mức độ độc tế bào dứa theo phần trăm RGR

Phân trăm RGR $\quad$ Độc tính (mức độ)

\begin{tabular}{|c|c|}
\hline$\geq 100$ & 0 \\
\hline $75-99$ & 1 \\
\hline $50-74$ & 2 \\
\hline $25-49$ & 3 \\
\hline $1-24$ & 4 \\
\hline 0 & 5 \\
\hline
\end{tabular}

Đánh giá di chuyển: Cấy $1,5 \times 10^{4}$ tê bào/giếng vào đĩa 6 giếng, ủ ở $37^{\circ} \mathrm{C}, 5 \% \mathrm{CO}_{2}$. Quan sát mỗi 24 giờ đến khi tế bào đạt độ bao phủ $>80 \%$ thì loại bỏ môi trường. Thay môi trường nuôi cấy không huyết thanh rồi để qua đêm nhằm bỏ đói tế bào. Loại bỏ môi trường trong giếng và tạo vùng trống vô bào bằng cách rạch một đường thẳng ở giữa giếng bằng một đầu típ $100 \mu$ l vuông góc với đáy đĩa. Rửa PBS 1 lần. Cho vào mỗi giếng $1,5 \mathrm{ml}$ dung dịch đã chuẩn bị ở từng nghiệm thức. Chụp ảnh tế bào trước và ngay sau khi tao ra đường rach, sau đó đưa tế bào trở lại tủ nuôi cây mô ở $37^{\circ} \mathrm{C}, 5 \%$ $\mathrm{CO}_{2}$. Chụp ảnh sau 24 giờ và so sánh các giếng. Đánh giá định lượng mức độ di chuyển của tể bào bằng phần mềm phân tích hình ảnh ImageJ 1.53e (Wayne Rasband, National Institutes of Health, USA). Mức độ di chuyển có thể được xác định gián tiếp bằng phần trăm diện tích vùng trống thời điểm 24 giờ so với diện tích vùng trống thời điểm 0 giờ. Từ đó, so sánh mức độ di chuyển của NBSN tiếp xúc với các nhóm dịch chiết và nhóm chứng. Diện tích vùng trông càng thu hẹp chứng tỏ tế bào di chuyển vào vùng này càng nhiều, đặc tính di chuyển của NBSN càng ít bị ảnh hưởng [5].

Xử lý thống kê: Số liệu sau khi thu nhận được nhập vào máy tính và xử lý với phần mềm thống kể SPSS phiên bản 20.0 (IBM, NY). Sử dụng kiểm dịnh One-Way ANOVA và kiểm định Independent Samples T Test để so sánh sự khác biệt của các nhóm giếng tế bào.

\section{KẾT QUẢ NGHIÊN CứU}

Đánh giá độc tính (Bảng 2). Độc tính tế bào in vitro của gel $\mathrm{CHX}$ phụ thuộc vào nông độ dịch chiết pha loãng. Dịch chiết gel $\mathrm{CHX}$ pha loãng $1 / 10^{3}$ và $1 / 10^{4}$ không gây độc tế bào in vitro (phần trăm RGR lớn hơn $70 \%$ ).

Bảng 2. Phần trăm RGR ở các nghiệm thức.

\begin{tabular}{|c|c|c|}
\hline Nghiệm thức & $\begin{array}{l}\text { Trung bình } \pm \\
\text { độ lệch chuẩn }\end{array}$ & $\begin{array}{l}\text { Mức độc } \\
\text { tính tế bào }\end{array}$ \\
\hline $\begin{array}{l}\text { Dịch chiết gel CHX } \\
0,5 \% \text { chưa pha loãng }\end{array}$ & $\begin{array}{l}30,343 \\
\pm 7,151\end{array}$ & 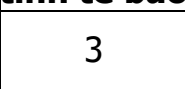 \\
\hline $\begin{array}{c}\text { Dịch chiết pha loãng } \\
1 / 10\end{array}$ & $\begin{array}{l}47,339 \\
\pm 5,989\end{array}$ & 3 \\
\hline $\begin{array}{c}\text { Dịch chiết pha loãng } \\
1 / 10^{2}\end{array}$ & $\begin{array}{l}56,844 \\
\pm 0,649\end{array}$ & 2 \\
\hline \begin{tabular}{|c|} 
Dịch chiết pha loãng \\
$1 / 10^{3}$
\end{tabular} & $\begin{array}{l}93,407 \\
\pm 1,001\end{array}$ & 1 \\
\hline $\begin{array}{c}\text { Dịch chiết pha loãng } \\
1 / 10^{4}\end{array}$ & $\begin{array}{c}100,807 \\
\pm 1,811\end{array}$ & 0 \\
\hline Chứng dương & $46,611 \pm 10,379$ & 3 \\
\hline Chứng âm & 100 & 0 \\
\hline
\end{tabular}

Đánh giá khả năng di cư (Bảng 3). Dich chiết gel CHX pha loãng $1 / 10^{3}$ và $1 / 10^{4}$ làm giảm đặc tính di chuyển của NBSN tương đương dịch chiết gel đối chiếu. Ảnh hưởng của dịch chiết gel $\mathrm{CHX} 0,5 \%$ đến khả năng di chuyển của NBSN phụ thuộc vào nồng độ pha loãng. Khả năng di chuyển của NBSN tăng theo độ pha loãng của dịch chiết gel $\mathrm{CHX}$. 
Bảng 3. Phân trăm diện tích vùng trống ở các nghiệm thức.

\begin{tabular}{|c|c|c|}
\hline \multirow{2}{*}{ Nghiệm thức } & \multicolumn{2}{|c|}{$\begin{array}{c}\text { Trung bình phân tram } \\
\text { diện tích vùng trống } \\
\text { (trung bình } \\
\text { chuẩn) }\end{array}$} \\
\cline { 2 - 3 } & 0 giộch \\
\hline Nhóm chứng dương & $100 \%$ & $0,951 \pm 1,648$ \\
\hline $\begin{array}{c}\text { Dịch chiết gel CHX } \\
\text { 0,5\% pha loãng } 1 / 10^{3}\end{array}$ & $100 \%$ & $65,657 \pm 14,228$ \\
\hline $\begin{array}{c}\text { Dịch chiết gel CHX } \\
\text { 0,5\% pha loãng } 1 / 10^{4}\end{array}$ & $100 \%$ & $43,591 \pm 14,575$ \\
\hline $\begin{array}{c}\text { Dịch chiết gel X pha } \\
\text { loãng 1/10 }\end{array}$ & $100 \%$ & $65,399 \pm 13,229$ \\
\hline $\begin{array}{c}\text { Dịch chiết gel } X \text { pha } \\
\text { loãng } 1 / 10^{4}\end{array}$ & $100 \%$ & $61,111 \pm 6,187$ \\
\hline
\end{tabular}

\section{BÀN LUÂN}

Chlorhexidine là một trong những chất kháng khuẩn tại chỗ hiệu quả nhất và được sử dụng rộng rãi trong điều trị bệnh nha chu. Tuy nhiên, nồng độ $\mathrm{CHX}$ trong túi nha chu thường giảm nhanh chỉ sau một thời gian ngắn. Gel in situ (gel hình thành tại chỗ) được chú ý phát triển trong những năm gần đây để duy trì tác dụng của $\mathrm{CHX}[2]$. Gel CHX nghiên cứu của chúng tôi là một loại gel in situ đảo ngược bởi nhiệt chứa $0,5 \% \mathrm{CHX}$ nhằm hỗ trợ điều trị viêm nha chu. Đặc điểm của chế phẩm này là công thức ở dạng lỏng trong điều kiện bảo quản và chuyển sang dạng gel trong điêu kiện sinh lý $\left(37^{\circ} \mathrm{C}\right)$.

Ớ nồng độ pha loãng $1 / 10^{3}$, kết quả nghiên cứu của chúng tôi cho thấy dịch chiết gel $\mathrm{CHX}$ không thể hiện độc tính lên NBSN khi phần trăm RGR > 70\% (99,358\%). Trong nghiên cứu của Marco Colombo và cs (2018), tác giả tiến hành thử nghiệm MTT để đánh giá độc tính của những nồng độ pha loãng hai loại gel có tên thương mại là Corsodyl Dental Gel ${ }^{\circledR}$ (Anh) chứa $1 \% \mathrm{CHX}$ và Plak Gel ${ }^{\circledR}(Y)$ chứa $0,2 \% \mathrm{CHX}$. Kết quả ghi nhận gel CHX thể hiện độc tính cao với NBSN in vitro sau 24 giờ. Phần trăm tế bào còn sống khoảng $31 \%$ dù chất thử nghiệm đã được pha loãng đến $1 / 10^{4}$ lần [6]. So với nghiên cứu của Colombo thì dịch chiết gel $\mathrm{CHX}$ trong nghiên cứu của chúng tôi thể hiện độc tính tế bào in vitro thấp hơn, không còn gây độc ở mức pha loãng $1 / 10^{3}$. Sự khác biệt với kết quả này có thể do thành phần tá dược trong gel không giống nhau.

Kết quả nghiển cứu hiện tại cho thấy khả năng di chuyển của NBSN tăng theo độ pha loãng dịch chiết gel $\mathrm{CHX}$. Diện tích vùng trống sau 24 giờ ở nhóm tế bào ủ với nhóm dịch chiết gel $\mathrm{CHX} 1 / 10^{4}$ nhỏ hơn nhóm dịch chiết gel $\mathrm{CHX}$
$1 / 10^{3}$ nhưng vẫn còn cao hơn diện tích ở nhóm chứng dương $(0,951 \%)$. Trong nhóm chứng dương, đường rạch gần như đã biến mất, chỉ còn 1 đĩa NBSN có diện tích vùng trống là 2,854\%. Tóm lại, dịch chiết gel CHX ở độ pha loãng an toàn với NBSN vẫn làm cản trở khả năng di chuyển của NBSN. Kết quả của nghiên cứu này phù hợp với một số nghiên cứu chứng minh $\mathrm{CHX}$ ức chế sự di chuyển in vitro của NBSN. Nghiên cứu của Sangeetha và cs (2020) đánh giá ảnh hưởng của dung dịch $\mathrm{CHX}$ lên quá trình di chuyển in vitro của nguyên bào sợi nướu ở những thời điểm khác nhau. Tác giả tạo ra đường rạch trong các đĩa nuôi cấy nguyên bào sợi và ủ với dung dịch $\mathrm{CHX} 0,1 \%$ trong 24,48 và 72 giờ. Kết quả cho thấy nguyên bào sợi khi tiếp xúc $\mathrm{CHX}$ có phần trăm di cư thấp hơn nhóm chứng. Tác giả kết luận $\mathrm{CHX}$ làm giảm đặc tính di chuyển của NBSN [7]. Mặc dù nước súc miệng chứa $\mathrm{CHX}$ được sử dụng rộng rãi trên lâm sàng, độc tính tế bào của $\mathrm{CHX}$ có thể làm suy giảm quá trình lành thương bằng việc ức chế sự di chuyển của tế bào in vitro. Mercan và cs (2019) đánh giá tác động của nước súc miệng chứa $\mathrm{CHX}$ (Andorex®, thổ Nhĩ Kỳ) lên một số đặc tính sinh học của NBSN, trong đó có khả năng di chuyển. Kết quả của nghiên cứu ủng hộ giả thuyết $\mathrm{CHX}$ ức chế sự di chuyển in vitro của NBSN [8].

Kết quả nghiên cứu dịch chiết gel CHX gây độc ở nồng độ $100 \%$ nhưng dịch chiết pha loãng $1 / 10^{3}$ và $1 / 10^{4}$ không còn gây độc tính in vitro lên NBSN. Dịch chiết ảnh hưởng lển đặc tính của NBSN khi làm giảm di chuyển tế bào và giảm co gel collagen. Tuy nhiên ảnh hưởng này tương đương gel đối chiếu chứa 0,2\% CHX (PerioKin ${ }^{\circledR}$ ). Thực tế gel Kin đã chứng minh hiêu quả trên lâm sàng trong những năm qua và làm tăng tốc độ lành thương[1]. Điều này có thể lý giải việc những chế phẩm chứa $\mathrm{CHX}$ thể hiện độc tính cao với tế bào in vitro nhưng vẫn an toàn khi sử dụng trên lâm sàng. Khi sử dụng gel trong môi trường miệng thì gel không tiếp xúc trực tiếp với tế bào mà qua mô liên kết hay được pha loãng bởi dich nướu.

$\mathrm{CHX}$ sử dụng thường xuyên trong lâm sàng sẽ dẫn đến phá hủy tế bào nhanh chóng. Tuy nhiên, độc tính tế bào in vivo dự kiến sẽ thấp hơn độc tính tế bào in vitro do môt số yếu tố bao gồm tổ chức mô nhiều lớp với các tế bào được bao quanh bởi nền ngoại bào, thuốc khuếch tán đễn hệ thống mạch máu, cơ chế bảo vê cơ thể và sự phức tap của môi trường miêng có nước bott sẽ nhanh chóng pha loãng chất kháng khuẩn [9]. Vì vậy, cần có thêm những 
nghiên cứu in vivo để xác nhận kết quả của nghiên cứu này.

\section{KẾT LUẬN}

Ảnh hưởng của gel $\mathrm{CHX}$ ở nồng độ pha loãng $1 / 10^{3}$ và $1 / 10^{4}$ lên một số đặc tính sinh học của NBSN tương đương gel đối chiếu (PerioKin ${ }^{\circledR}$ ) được sử dụng hiệu quả trên lâm sàng hiện nay. Gel nghiên cứu của chúng tôi là một loại gel đảo ngược bởi nhiệt có ưu điểm làm tăng thời gian lưu trú của hoạt chất và tăng hiệu quả điều trị.

LỜI CẢM ƠN: Cám ơn TS Huỳnh Trúc Thanh Ngọc-Khoa Dược, ĐHY Dược TP.HCM đã cung cấp mẫu nghiên cứu cho chúng tôi.

\section{TÀI LIẸU THAM KHẢO}

1. Ban Zuhair A. (2020), "The Efficacy of Chlorhexidine Gel as an Adjunctive Treatment for Patient with Chronic Periodontitis", Indian Journal of Forensic Medicine \&amp; Toxicology. 14(1), pp. 544-550.

2. Garala K., Joshi P., Shah M., Ramkishan A. and Patel J. (2013), "Formulation and evaluation of periodontal in situ gel", Int J Pharm Investig. 3(1), pp. 29-41.

3. Nie S., Hsiao W. L., Pan W. and Yang $Z$. (2011), "Thermoreversible Pluronic F127-based hydrogel containing liposomes for the controlled delivery of paclitaxel: in vitro drug release, cell cytotoxicity, and uptake studies", Int J Nanomedicine. 6, pp. 151-66.

4. Li R., Guo W., Yang B., Guo L., Sheng L., Chen G., Li Y., Zou Q., Xie D., An X., Chen Y. and Tian W. (2011), "Human treated dentin matrix as a natural scaffold for complete human dentin tissue regeneration", Biomaterials. 32(20), pp. 4525-38.

5. Liang C. C., Park A. Y. and Guan J. L. (2007), "In vitro scratch assay: a convenient and inexpensive method for analysis of cell migration in vitro", Nat Protoc. 2(2), pp. 329-33.

6. Colombo M., Ceci M., Felisa E., Poggio C. and Pietrocola G. (2018), "Cytotoxicity evaluation of a new ozonized olive oil", European journal of dentistry. 12(4), pp. 585-589.

7. Sukumaran S. K., Vadakkekuttical R. J. and Kanakath H. (2020), "Comparative evaluation of the effect of curcumin and chlorhexidine on human fibroblast viability and migration: An in vitro study", J Indian Soc Periodontol. 24(2), pp. 109-116.

8. Mercan U., Gonen Z. B., Salkin H., Yalcin Ulker G. M. and Meral D. G. (2019), "Comparison of the effect of postoperative care agents on human gingival fibroblasts: a preliminary study", Eur Oral Res. 53(2), pp. 67-73.

9. Cabral C. T. and Fernandes M. H. (2007), "In vitro comparison of chlorhexidine and povidoneiodine on the long-term proliferation and functional activity of human alveolar bone cells", Clin Oral Investig. 11(2), pp. 64-155.

\section{KIẾN THỨC, THỰC HÀNH VỀ CHĂM SÓC TRƯớC SINH VÀ MộT SỐ YẾU TỐ LIÊN QUAN Ở PHU NỮ Có CON DƯớI 6 THÁNG TUỔI TẠI 2 XÃ/PHƯỜNG TỈNH THỪA THIÊN HUẾ NĂM 2019}

\section{TÓM TẮT}

Muc tiêu: Nghiên cứu mô tả cắt ngang được thực hiện ở 2 xã/phường của tỉnh Thừa Thiên Huế năm 2019 nhằm mô tả kiến thức và thực hành của phu nữ có con dưới 6 tháng tuổi về chăm sóc trước sinh và một số yếu tố liên quan. Đối tượng và phương pháp: Đối tượng là bà mẹ có con dưới 6 tháng tuổi. Sử dụng bộ câu hỏi có cấu trúc, kiến thức và thực hành được đánh giá dựa trên Hướng dẫn quốc gia về các dịch vụ chăm sóc sức khỏe sinh sản của Bộ Y tế. Kết quả: Kết quả cho thấy tỷ lệ bà mẹ có kiến thức tốt và thực hành tốt về chăm sóc trước sinh lần lượt là

\footnotetext{
${ }^{1}$ Bệnh Viện Đa Khoa Quốc Tế Hoàn Mỹ Thủ Đức, Thành phố Hồ Chí Minh

${ }^{2}$ Trường Đại học Y Dược, Đại học Huê

Chịu trách nhiệm chính: Nguyễn Thị Nga

Email: nganguyen@huemed-univ.edu.vn

Ngày nhận bài: 3.3.2021

Ngày phản biên khoa học: 23.4.2021

Ngày duyệt bài: 5.5.2021
}

\begin{abstract}
Nguyễn Thị Bích Trâm ${ }^{1}$, Nguyễn Thị $\mathbf{N g a}^{2}$
$60,8 \%$ và $63,1 \%$. Trình độ học vấn, nghề nghiệp, số lần sinh con là những yếu tổ có liên quan đến kiến thức tốt. Các yếu tố liên quan đến thực hành tốt bao gồm: trình độ học vấn, nghề nghiệp, nơi sinh sống, số lần mang thai, số lần sinh con và kiến thức về chăm sóc trước sinh $(p<0.05)$. Kết luận: Do vậy, cần tăng cường truyền thông giáo dục sức khỏe, tư vấn cho phu nữ trước và trong khi mang thai để phu nữ có kiến thức đúng và đây đủ, từ đó thực hành tốt chăm sóc trước sinh.
\end{abstract} hành

Tư khóa: Chăm sóc trước sinh; kiến thức; thực

\section{SUMMARY}

KNOWLEDGE, PRACTICES OF ANTENATAL CARE AND ASSOCIATED FACTORS AMONG WOMEN WHO HAD CHILDREN AGED UNDER 6-MONTH AT 2 COMMUNES/WARDS OF

THUA THIEN HUE PROVINCE IN 2019

A cross-sectional descriptive study was conducted at 2 communes/wards of Thua Thien Hue province in 2019 to describe the knowledge and practices of 